\section{Supplementary Suckling Technique for Relactation in Infants With Severe Acute Malnutrition}

We report on use of supplementary suckling technique in 62 infants [mean (SD) age 2.5 (1.3) mo] with severe acute malnutrition admitted at our Nutritional rehabilitation Center. It was successful in $34(55.7 \%)$ infants.

Keywords: Lactation failure, Management, Protein energy malnutrition.

Almost 13.6\% infants below the age of 6 months in Uttar Pradesh, India are severely malnourished [1]. Almost 20\% children with Severe acute malnutrition (SAM) admitted to our Nutritional Rehabilitation Center (NRC) were $<6$ mo of age [2]. The most important cause of SAM in infants $<6$ months is lack of exclusive breast feeding because of cultural and traditional practices, illiteracy, lack of antenatal counseling and other factors [3].

We tried Supplementary suckling technique (SST) in such mothers (with lactation failure) of infants aged $<6$ months with SAM admitted in our NRC after counseling on positioning and attachment failed to establish lactation. SST was not tried in mothers who had not breastfed their infants at all in last $4 \mathrm{wks}$. In this technique, one end of a 6 or $8 \mathrm{~F}$ feeding tube is stuck to the mother's breast close to the nipple and the other end of the tube lies in a bowl of milk (expressed breast milk or diluted F-100) kept lower than the mother's breast while the infant suckles at the mother's breast [4]. The sucking stimulates milk production in the mother and simultaneously the baby draws milk from the bowl through the tube satisfying its needs. SST was considered successful if the mother's milk production increased and the baby started gaining weight on exclusive breastfeeding. If relactation was not successful in the mother and we were not able to shift the baby to exclusive breastfeeding it was considered to be a failure of SST. The duration for which SST was tried ranged from 7-14 d.

A total of 108 children $<6$ mo were admitted in the NRC over the study period. We tried SST in $62(57.4 \%)$ infants. The mean (SD) age at admission was 2.5 (1.3) mo (46 infants $\leq 3 \mathrm{mo}$ and 16 infants $>3 \mathrm{mo}$ ). The most common presenting complaint was acute diarrhea (23), followed by failure to gain weight (15). The average (SD) weight gain in the infants at discharge was $10.9(8.3) \mathrm{g} / \mathrm{kg} /$ d. The SST was successful in $34(55.7 \%)$ infants, and failed in $27(43.5 \%)$ and 1 infant died during treatment. The failures included those babies who could not be shifted back to exclusive breastfeeding or those in whom SST could not be continued as their mothers left the hospital before establishment of relactation.

Relactation is a challenge which requires motivation not only of the mother but also of the staff involved in counseling [5]. SST is a technique to tackle this difficult situation and induce relactation. We had encouraging results with SST with $>50 \%$ mothers successfully establishing relactation resulting in good weight gain in their infants. Similar observations were made by Vygen, $e t$ $a l$. [6] by adopting SST in their NRC.

SST has been found to be effective in an inpatient setting. Feasibility and utility of such an approach in inducing relactation in mothers at community level need to be investigated.

Contributors: DKS was involved in collection of data, analysis and writing the manuscript. RR and SD were involved in data analysis and manuscript revision.

Funding: None; Competing interests: None stated.

\section{DK Singh, Ruchi Rai and Shashi Dubey Department of Pediatrics, MLN Medical College, Allahabad, UP, India. ruchiraialld@gmail.com}

\section{REFERENCES}

1. National Family Health Survey-3, India 2005-06. Ministry of Health and Family Welfare, Government of India. Available from: www.measuredhs.com/pubs/pdf/FRIND3/ FRIND3-Vol 1.pdf. Accessed February 20, 2014.

2. Singh DK, Rai R, Mishra PC, Maurya M, Srivastava A. Nutritional rehabilitation of children $<6 \mathrm{~m}$ with SAM. Indian J Pediatr. 2013; Nov 23 [ Epub ahead of print].

3. Bansal CP. Breastfeeding - Why are we still failing? Indian Pediatr. 2013;50:993-4.

4. Operational Guidelines on Facility Based Management of Children with Severe Acute Malnutrition, Ministry of Health and Family Welfare, Government of India, 2011. Available from: www.nihfw.org/pdf/NCHRC/publications. Accessed February 20, 2014.

5. Lelijveld N, Mahebere-Chirambo C, Kerac M. Career and staff perspectives on supplementary suckling for treating infant malnutrition: qualitative findings from Malawi. Matern Child Nutr. 2013. [Epub ahead of print].

6. Vygen SB, Roberfroid D, Captier V, Kolsteren P. Treatment of severe acute malnutrition in infants aged $<6$ months in Niger. J Pediatr. 2013;162:515-21. 